\title{
Three Dimensional Plastic Stress Analysis of Reactor Pressure Vessel Nozzle Belt
}

\author{
Lu Wei ${ }^{*}$, Wang Xuwei and Yang Peiyong \\ State Nuclear Power Technology R\&D Center (Beijing), Beijing 100190
}

Keywords: Reactor pressure vessel, Nozzle belt, Actual material stress-strain relationship, Multi-linear kinematic hardening, Plastic limit load

Abstract. Reactor pressure vessel (RPV) is exposed to deadweight, pressure, heat expansion, seismic load, pipe loads and etc under operating, accident and hydrostatic test conditions. Due to geometric discontinuity, the nozzle belt is reluctant to stress concentration, which is the key part in structure analysis. Linear elastic analysis method is dominant in present research of RPV stress analysis. While in some severe cases, it may obtain results which don't satisfy regulations due to the conservative prediction of linear method. Plastic analysis can obtain more reasonable results. In present research, a multi-linear kinematic hardening constitutive model of Ansys with an input of actual material stress-strain relationship is used to simulate the plastic behaviors of RPV nozzle belt. Stress distribution, extension of plastic region and the plastic limit load is obtained which provides theoretical basis for RPV design.

\section{Introduction}

As part of the pressure boundary of primary loop, Reactor Pressure Vessel (RPV) is the containment and support the core, and provides the coolant channel for core fuel elements. As one of the most critical barrier of PWR, RPV is exposed to high temperature, high pressure and irradiation. The structure integrity of RPV under all kinds of operational states and accident conditions needs to be assured when design. RPV mainly consists of closure head, nozzle belt, core belt, lower head and sealing flanges. RPV inferfaces with the reactor internals, primary loop piping, safety injection piping, head venting piping and steel structures from the integrated head package and is supported by the reactor vessel supports on the containment building concrete structure.

RPV is designed to bear deadweight, pressure, thermal expansion, seismic load, pipe load and etc. Due to the geometric discontinuity, the nozzle belt is reluctant to failure induced by stress concentration, which is one of the critical issues of RPV structure integrity.

Linear elastic analysis method is dominant in present research of RPV stress analysis. Xu Dinggeng [1] et. al. built 3D model of local part of RPV nozzle belt and carried out a transient linear elastic analysis, in which RPV shell is simplified as half model and the nozzle is simplified as full model, and the effect of adjacent nozzles is neglected. Yang Wen [2] built the local model of RPV shell and outlet nozzle, and carried out an elastic analysis and stress assessment. Wang Junwei [3] and Zhu Yongbo [4] bulit 1/3 and 1/2 RPV model respectively, and carried out the stress analysis and assessment in design condition according to RCC-M. Yang Wen [5] discussed the full-scale modelling method by TSV software and the stress analysis of full-scale RPV with linear elastic material model.

During all kinds of working conditions, plastic behaviors of RPV material may occur. The plastic behaviors can not be obtained by the general elastic stress analysis, so that plastic method should be introduced. Besides, in some harsh conditions, linear elastic assessment results may not meet the corresponding code requirements as the elastic analysis will lead to a conservative results, while the plastic method will lead to results closer to the real case. By plastic analysis, the elastic-plastic behaviors of RPV in some harsh conditions can be obtained. Besides, the plastic limit load to prevent plastic collapse of RPV can be obtained. Engineering experiences show that the failure of RPV generally related to the plastic limit load and elastic-plastic fracture. Whether the failure mode of RPV is plastic collapse or elastic-plastic fracture, the plastic limit load is one of the key parameters of RPV safety assessment. Plastic analysis of RPV nozzle belt is important to its safety analysis. 


\section{FEM Modeling}

The present 3D RPV nozzle belt model is shown as in Figure 1 3, including the RPV shell, the outlet and inlet nozzle and RPV supports. To eliminate the boundary effect, RPV shell and the nozzle are extended to a length which satisfy

$\mathrm{L} \geq 2.5 \sqrt{\mathrm{R} \delta}$

in which, $\mathrm{R}$ is radius of RPV shell and $\delta_{\text {is the shell thickness. }}$

The RPV model is meshed with Solid 185 in ANSYS, and the region of nozzle belt and the nozzles are refined. The FEM model consists of 57210 nodes and 207530 elements.

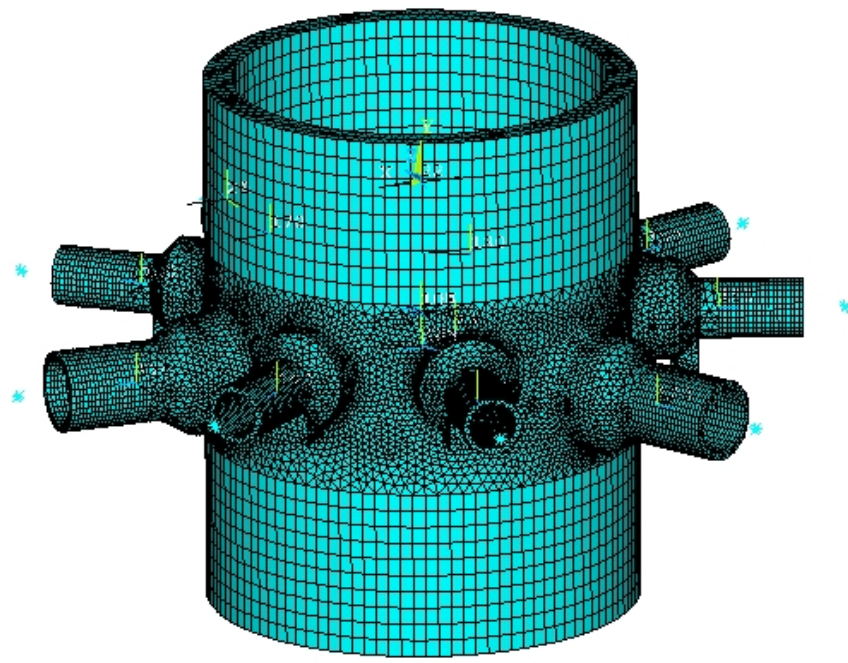

Fig. 1 FEM model of RPV nozzle belt

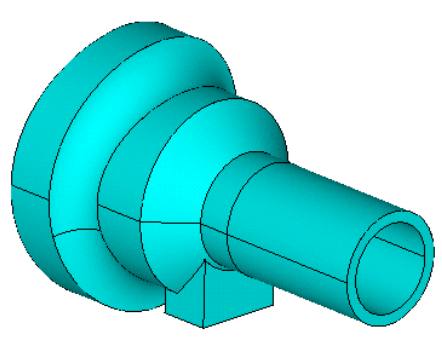

Fig. 2 Inlet Nozzle

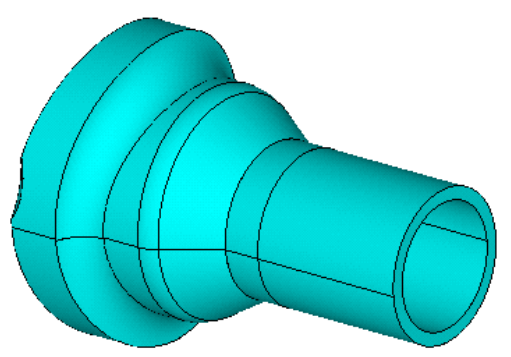

Fig.3 Outlet Nozzle

\section{Material and Constitutive Model}

Material Properties. The mechanical properties of RPV material which is SA508 Cl.3 Gr.1 Steel are listed as in Table 1 according to ASME BPVC II-2007 [6].

Table 1 Material Property Parameters of SA508 Cl.3 Gr.1 Steel

\begin{tabular}{|c|c|c|c|c|c|c|}
\hline $\begin{array}{c}\text { Temp. } \\
{ }^{\circ} \mathrm{C}\end{array}$ & $\begin{array}{c}\mathrm{S}_{\mathrm{m}} \\
\mathrm{MPa}\end{array}$ & $\begin{array}{c}\mathrm{S}_{\mathrm{y}} \\
\mathrm{M} \mathrm{Pa}\end{array}$ & $\begin{array}{c}\mathrm{E} \\
\times 10^{3} \mathrm{M} \mathrm{Pa}\end{array}$ & $\mathrm{v}$ & $\begin{array}{c}\mathrm{TE} \\
10^{-6} /{ }^{\circ} \mathrm{C}\end{array}$ & $\begin{array}{c}\mathrm{TC} \\
\mathrm{V} /(\mathrm{m} \cdot \mathrm{K})\end{array}$ \\
\hline 21 & 184.1 & 344.8 & 191.7 & 0.3 & 11.5 & 40.6 \\
\hline 38 & 184.1 & 344.8 & 190.6 & 0.3 & 11.7 & 40.8 \\
\hline 93 & 184.1 & 324.1 & 186.8 & 0.3 & 12.1 & 40.8 \\
\hline 148 & 184.1 & 313.7 & 184.1 & 0.3 & 12.4 & 40.5 \\
\hline 204 & 184.1 & 304.8 & 180.0 & 0.3 & 12.8 & 39.9 \\
\hline 260 & 184.1 & 297.9 & 177.2 & 0.3 & 13.1 & 39.3 \\
\hline 315 & 184.1 & 290.3 & 173.7 & 0.3 & 13.3 & 38.4 \\
\hline 343 & 184.1 & 286.1 & 171.7 & 0.3 & 13.5 & 37.9 \\
\hline
\end{tabular}


in which $S_{m}$ is allowable strength, $S_{y}$ is yield strength, E is elastic module, $v$ is Possion ratio, TE is the linear expansion coefficient and TC is the thermal conductivity coefficient.

Elastic-plastic Constitutive Model. Simplified stress-strain relationships can be adopted in plastic analysis generally like ideal elastic-plastic model, linear hardening model. While in present research the real stress-strain relationship is adopted to characterize the actual RPV plastic behaviors. As shown in Figure 4 is the SA508 Cl.3 Gr.1 steel stress-strain relationship curve. Multilinear Kinematic Hardening Plasticity model of ANSYS is used to characterize the constitutive law of RPV material, in which Besseling effect is considered.

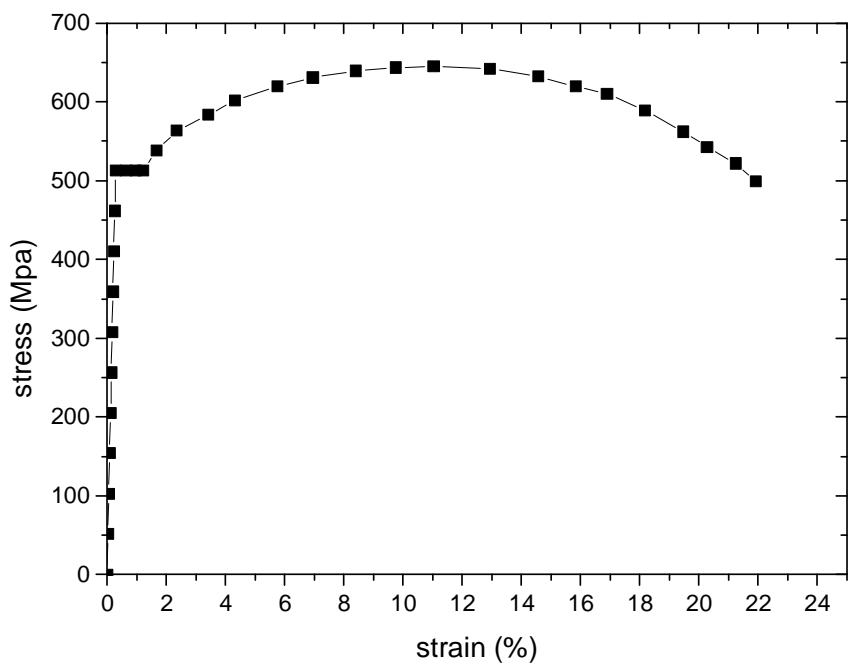

Fig.4 Actual Stress-strain Relationship Curve of SA508 Cl.3 Gr.1 Steel

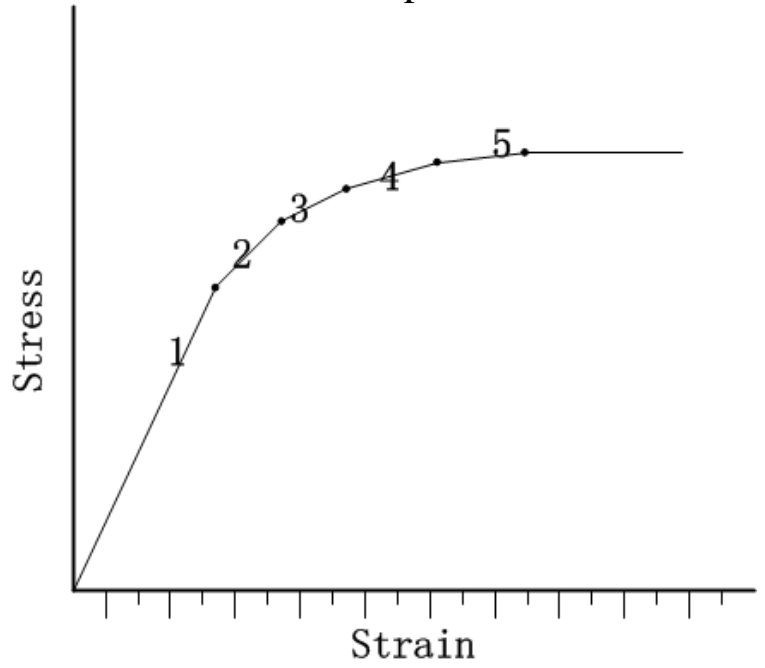

Fig.5 Multi-linear Kinematic Hardening Model

Boundary Conditions and Loads. RPV shell interfaces with the support rings through supports underneath inlet nozzles. The support boundary constrains the axial displacement of RPV supports. Internal pressures are applied to inner surfaces of RPV shell and nozzle. Equivalent pressure load boundaries are applied to the end sections of RPV shell and nozzle, which meet

$$
\mathrm{p}_{1}=\frac{\mathrm{pR}_{\mathrm{i}}^{2}}{\mathrm{R}_{\mathrm{o}}^{2}-\mathrm{R}_{\mathrm{i}}^{2}}, \quad \mathrm{p}_{2}=\frac{\mathrm{pr}_{\mathrm{i}}^{2}}{\mathrm{r}_{\mathrm{o}}^{2}-\mathrm{r}_{\mathrm{i}}^{2}}
$$

$\mathrm{R}_{\mathrm{o}}, \mathrm{R}_{\mathrm{i}}$ are outer and inner radius of RPV shell respectively; ${ }^{r_{o}}, r_{i}$ are outer and inner radius of nozzle respectively. 
The elastic-plastic behaviors of RPV nozzle belt under internal pressure are calculated. Incremental algorithm is used to solve the nonlinear problem. Iterative solution is performed for each load step. When reach the yield strength, small increment step is adopted.

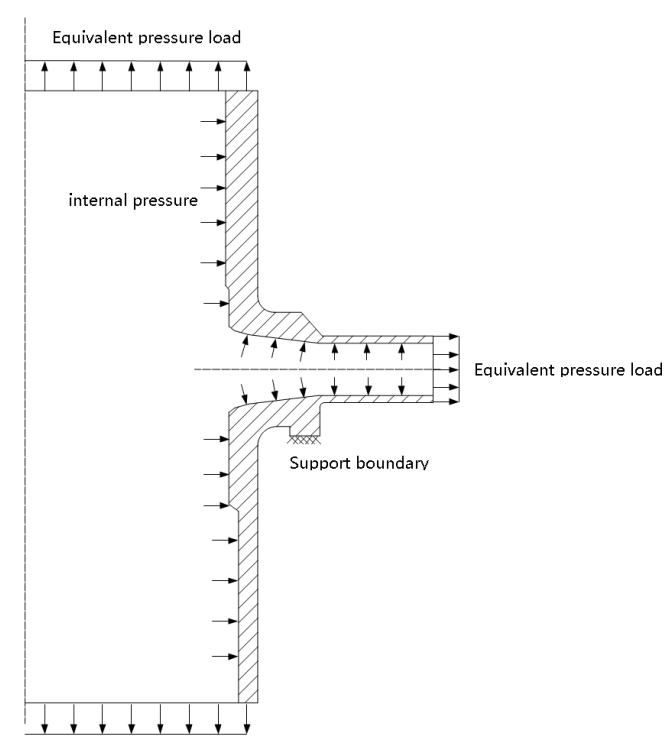

Fig.6 Boundary Conditions of RPV Nozzle Belt

\section{Results and Discussion}

Elastic Stress Distribution. Under the internal pressure of $\mathrm{p}=22.5 \mathrm{Mpa}$, the nozzle belt of RPV is in elastic state. As shown in Figure 7 8 is Mises stress distribution of vertical section of inlet and outlet nozzles. The stress concentration is evident in the intersection of the nozzles and RPV shell, and Mises stress decreases with the axial distance (z). The maximum Mises stress of outlet nozzle is $453.6 \mathrm{Mpa}$, and of the inlet nozzle is $423.9 \mathrm{Mpa}$. The membrane stress of RPV shell is

$$
\sigma_{\mathrm{m}}=\frac{\mathrm{pD}}{2 \delta}=84.7 \mathrm{Mpa}
$$

In this case, the stress intensity factors of outlet and inlet nozzle are

$$
\begin{gathered}
\mathrm{SCF}_{\text {outlet }}=\frac{\left(\sigma_{\text {outlet }}\right)_{\max }}{\sigma_{\mathrm{m}}}=5.4 \\
\mathrm{SCF}_{\text {outlet }}=\frac{\left(\sigma_{\text {inlet }}\right)_{\max }}{\sigma_{\mathrm{m}}}=5.0 .
\end{gathered}
$$

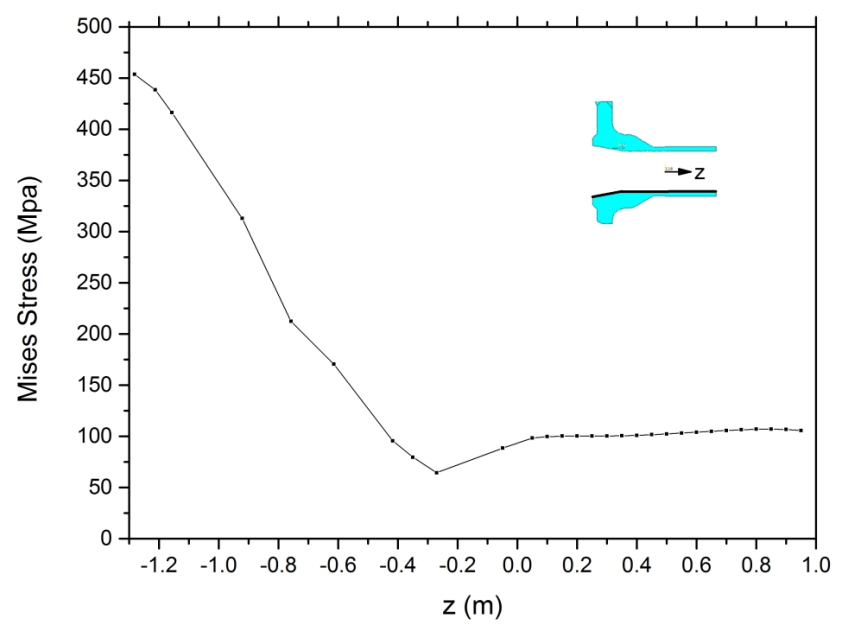

Fig.7 Mises Stress Distribution of Vertical Section of Outlet Nozzle 


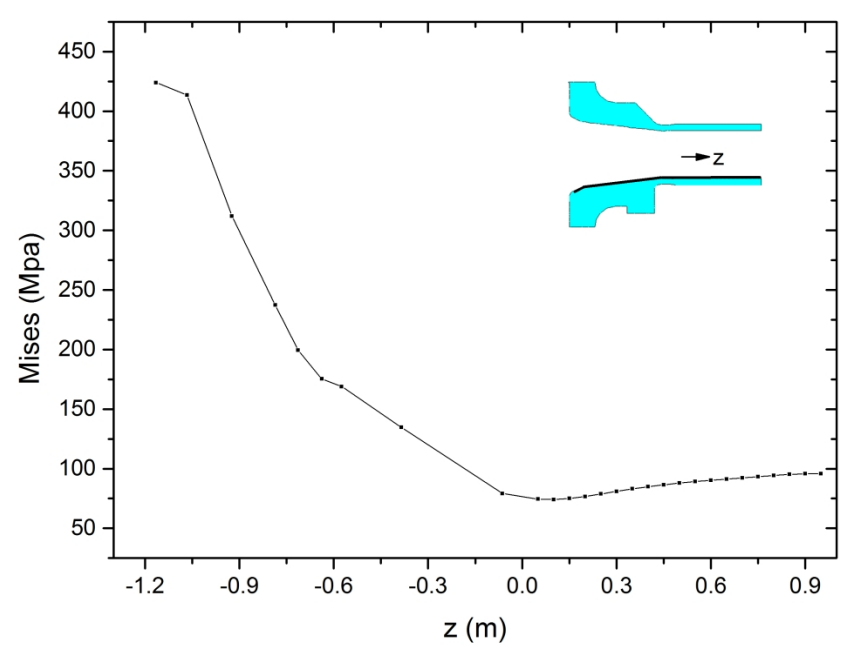

Fig.8 Mises Stress Distribution of Vertical Section of Inlet Nozzle

Propagation of Plastic Region. Figure 9(a) (d) give the Mises stress nephogram of outlet nozzle when $\mathrm{p}=9 \mathrm{Mpa}, 22.5 \mathrm{Mpa}, 27 \mathrm{Mpa}, 31.5 \mathrm{Mpa}$. At the beginning of the loading process, the nozzle belt is in elastic state. The maximum stress occurs at the intersection of the nozzle and RPV shell. When the pressure load exceeds $22.5 \mathrm{Mpa}$, the inner surface of outlet nozzle adjacent to RPV shell reaches to the yield strength first. As the pressure load increases, the plastic region of the outlet nozzle inner surface expands. And RPV shell in the intersection region goes to plastic state at the same time. As the pressure load increases to the limit load, the plastic region of the nozzle belt will expands accordingly, until the whole nozzle intersection loss bearing capacity.

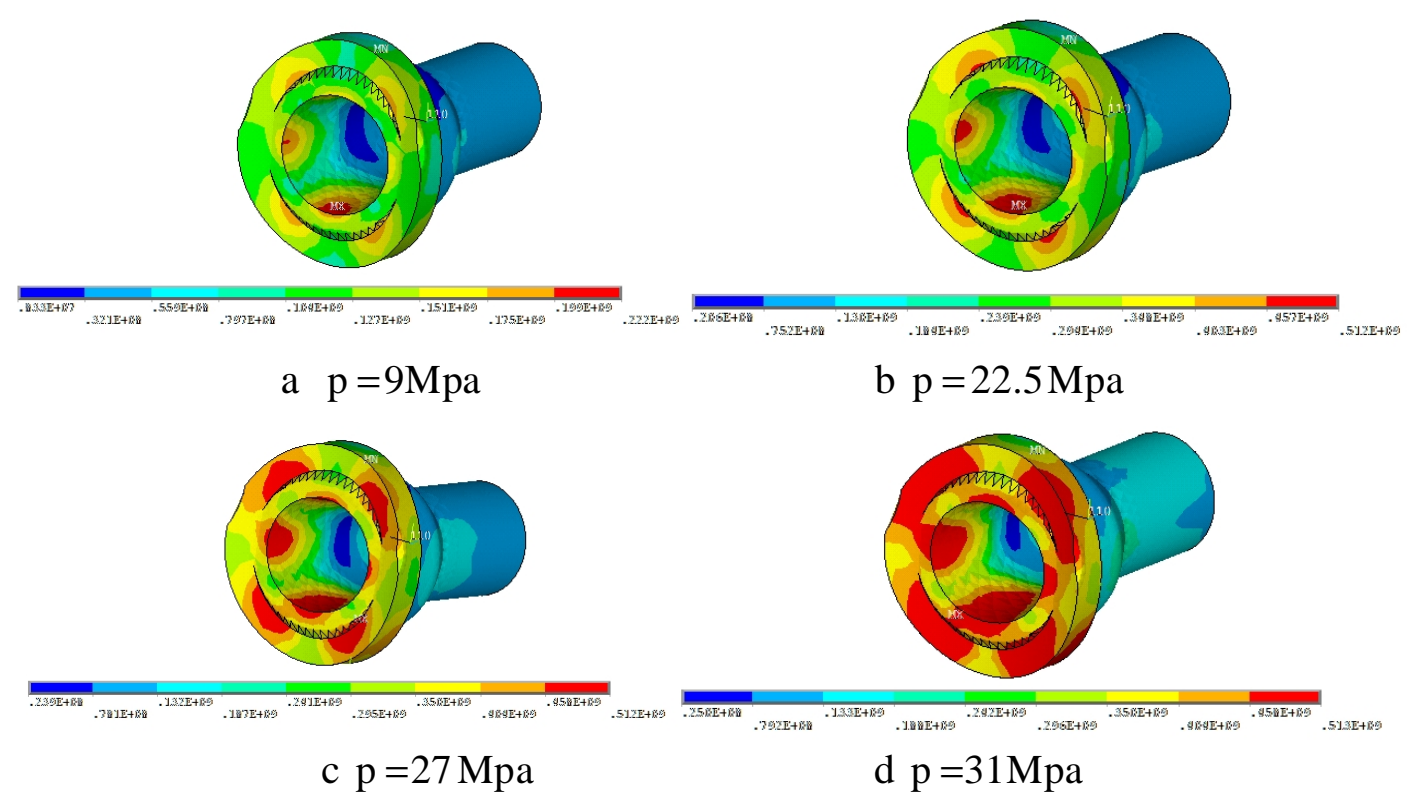

Fig.9 Mises Stress Nephogram of Outlet Nozzle

Figure 10 gives the stress-load relationship of typical outlet and inlet nozzle location. It can be seen that stresses of typical location 1 4 increases with loads linearly first; when the pressure load exceeds 22.5 Mpa, they will reach the yield strength; when the pressure load exceeds $40 \mathrm{Mpa}$, stress hardening occurs. 


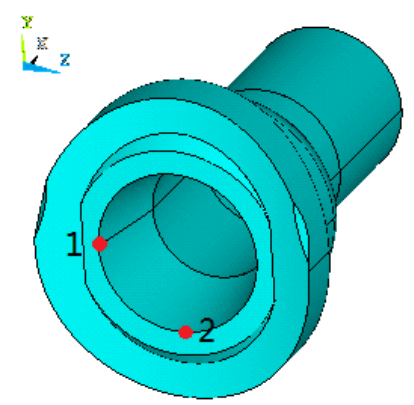

a

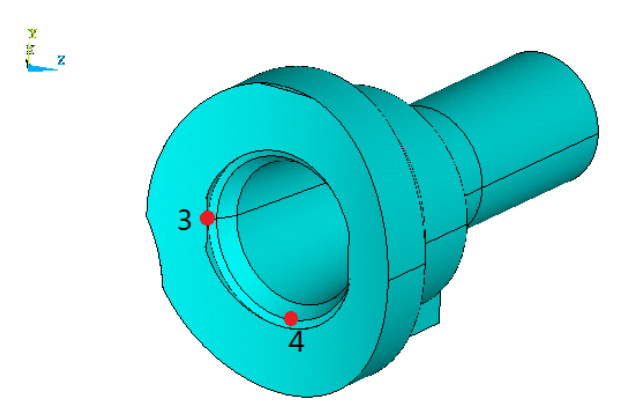

b

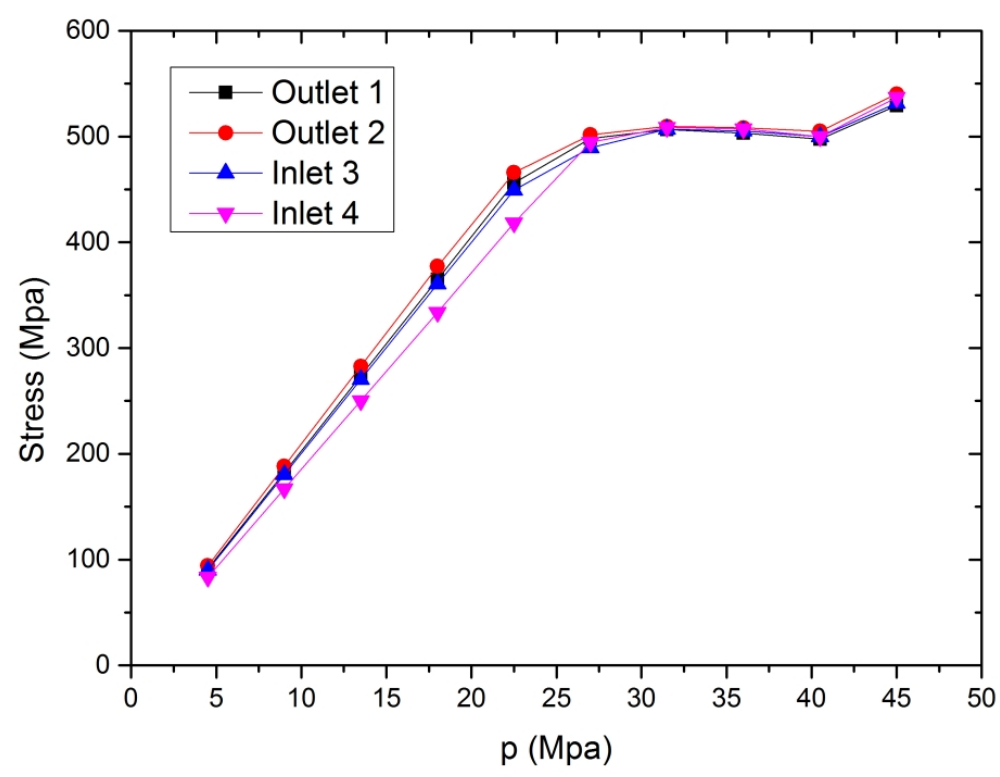

c

Fig.10 Mises Stress Relationship with Loads of Typical Location

(a Typical Location of Outlet Nozzle; b Typical Location of Inlet Nozzle; c Stress-load Relationship)

Plastic Limit Load. The plastic limit load can be obtained by strain/ displacement-load curve of typical location. Stress analysis results show the stress concentration decreases with the axial distance $\mathrm{z}$, which means the intersection of RPV shell and nozzle is the concerned region. The plastic propagation results show that typical location 2 on the vertical section of outlet nozzle goes to plastic state first. So the strain-load relationship of typical location 2 is adopted as shown in Figure 11.

Both twice-elastic-slope method and tangent intersection method are used to decide the plastic limit load. The plastic limit load calculated by twice-elastic-slope method is

$$
\mathrm{P}_{2 \theta}=40.45 \mathrm{Mpa}
$$

The plastic limit load calculated by tangent intersection method is

$$
\mathrm{P}_{\mathrm{T}}=39.30 \mathrm{Mpa}
$$

The minimum value of $\mathrm{P}_{2 \theta}$ and $\mathrm{P}_{1}$ is taken as the plastic limit load from a conservative point of view. 


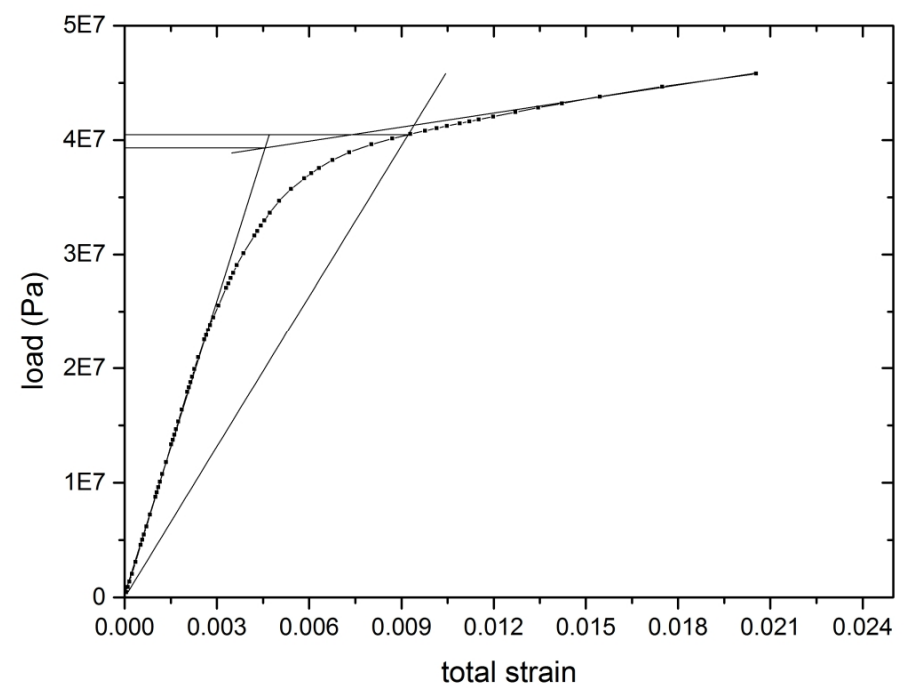

Fig.11 1st Principal Strain-Load Curve of Outlet Nozzle Typical Location 2

\section{Conclusion}

Three dimensional FEM model of RPV nozzle belt is built in present research, with considering the nonliearity of RPV material. A multi-linear kinematic hardening constitutive model of Ansys with an input of actual material stress-strain relationship is used to simulate the plastic behaviors of RPV nozzle belt.

Results show that stress concentration will occur at the intersection region of RPV shell and the nozzles, and the Mises stress decreases with axial distance evidently. The inner surface of outlet nozzle adjacent to RPV shell reaches to the yield strength first and the plastic region expands accordingly as the load increases. Stress of typical location of nozzles increases with the applying load linearly first, and goes into the state of plastic flow, and then stress hardening occurs. The plastic limit load are calculated by two methods from strain-curve of typical location, and the minimum value is adopted from a conservative point of view.

\section{Acknowledgments}

The research is sponsored by Chinese Major National Science and Technology Project (2012ZX06004-012).

\section{References}

[1] Xu Dinggeng, Wang Baisong. Tri-dimensional finite element analysis of transient stress field of PWR pressure vessel nozzle belt. Chinese Journal of Nuclear Science and Engineering, 7 (1987) 313-317.

[2] YANG Wen, ZHENG Lian-gang, YANG Yu. Stress and Fatigue Analysis for Outlet Nozzle of Nuclear Reactor Pressure Vessel. Atomic Energy Science and Technology, 42 (2008) 505-508.

[3] WANG Junwei, ZHANG Zhouhong,WU Gaofeng, FAN Liming. Reactor Vessel Stress Analysis for CPR1000 Nuclear Power Plant. Atomic Energy Science and Technology, 42 (2008) 495-499.

[4] Zhu Yongbo, Zhai Lihong. Analyse and Evaluate Outlet Nozzles of Reactor Pressure Vessels. CFHI Technology, 6(2012) 51-54. 
[5] Yang Wen, Zhang Liming, Zhen Liangang. Numerical Simulation Research on Integral Model of Nuclear Reactor Pressure Vessel. 15th National Symposium on Nuclear Plant Structure Mechanics, 2008, 335-339.

[6] ASME. ASME boiler and pressure vessel code II, 2007. 